\title{
A study of capillary pericyte viability on extracellular matrix produced by endothelial cells in high glucose
}

\author{
E. Beltramo, S. Buttiglieri, F. Pomero, A. Allione, F. D’Alù, E. Ponte, M. Porta \\ Department of Internal Medicine, University of Turin, Torino, Italy
}

\begin{abstract}
Aims/hypothesis. Thickening of the basement membrane and selective loss of pericytes occur early in diabetic retinopathy. As we showed previously that pericyte adhesion is impaired on extracellular matrix produced by endothelial cells in high hexose concentrations, we aimed to verify if altered adhesion could influence pericyte viability and replication.

Methods. Conditioned extracellular matrices were obtained by growing human umbilical vein endothelial cells in media containing $28 \mathrm{mmol} / \mathrm{l} \mathrm{D}$-glucose, with or without the inhibitors of protein glycation thiamine or aminoguanidine, and D-galactose or L-glucose up to $28 \mathrm{mmol} / \mathrm{l}$. Having removed the endothelium, bovine retinal pericytes were grown on these matrices and, in separate experiments, on laminin, fibronectin or type IV collagen. Pericyte viability and replication were measured by cell counts and DNA synthesis after 7 days, cell cycle traversal after 2 days and apoptosis after 18 h, 2 days and 7 days.
\end{abstract}

Results. Pericyte counts and DNA synthesis were reduced on matrices produced in high D-glucose and Dgalactose, whilst matrix obtained in L-glucose reduced DNA synthesis but not counts. Both thiamine and aminoguanidine corrected reduced pericyte viability when added to high D-glucose. Cell cycle and apoptosis were not affected by growing pericytes on different conditioned matrices. Laminin, fibronectin and type IV collagen did not modify pericyte replication. Conclusions/interpretations. Reduced pericyte counts could depend on impaired initial adhesion to the extracellular matrix produced by endothelium in high hexose concentrations, rather than impaired replication or viability. Altered cell-matrix interactions might facilitate pericyte dropout in diabetic retinopathy, independently of the effects of high glucose on pericyte replication. [Diabetologia (2003) 46:409-415]

Keywords Diabetic retinopathy, extracellular matrix, pericytes, endothelium, glucose, galactose, aminoguanidine, thiamine, glycation.
Thickening of the basement membrane is an early event in the course of diabetic microangiopathy $[1,2]$

Received: 12 June 2002 / Revised: 6 November 2002

Published online: 26 February 2003

C) Springer-Verlag 2003

Corresponding author: E. Beltramo PhD, Department of Internal Medicine, University of Turin, C.so AM Dogliotti 14, 10126 Torino, Italy

E-mail: elena.beltramo@unito.it

Abbreviations: ECM, extracellular matrix; M199, Medium 199

Hepes modification; BRP, bovine retinal pericytes; ECGS, Endothelial Cell Growth Supplement; BrdU, 5-bromo-2'-deoxyuridine; TMB, tetramethylbenzidine. and is observed in other forms of hyperhexosaemia, such as galactose-fed rats, which also develop a diabetic-like retinopathy $[3,4]$. The evolution of diabetic retinopathy is strongly influenced by qualitative and quantitative changes in the extracellular matrix (ECM) of the capillary basement membrane. In particular, alterations of some ECM components were shown to influence the characteristics of endothelium [5] and ECM-associated growth factors [6], although the mechanisms are still unclear.

Endothelium is likely to represent the major contributor to the synthesis of capillary ECM material. In particular, endothelial cells were found to increase their synthesis of type IV collagen and fibronectin 
when cultured in high glucose concentrations $[5,7]$ and ECM produced in high glucose was reported to reduce endothelial cell replication, even without high ambient glucose, possibly through increased cellECM adhesion and cytoskeletal rearrangements [5]. As structural components of the ECM, such as collagen, are the prime targets of advanced glycation processes [8], cross-link formation induced by AGE could cause stiffness of the basement membrane and impair tissue remodelling [9].

However, loss of endothelial cells is a later event of diabetic retinopathy, usually associated with capillary non perfusion [10], whereas selective loss of pericytes, which are embedded within the ECM, is thought to occur earlier [11], possibly along with basement membrane thickening.

We have previously shown that pericyte adhesion is impaired on ECM produced by endothelial cells in high hexose concentrations [12]. The aim of this study was to further investigate if abnormal ECMs produced by endothelial cells cultured in high hexose concentrations influence pericyte viability, i.e. their replication, cell cycle traversal and apoptosis rate.

\section{Materials and Methods}

Reagents. All reagents were purchased from Sigma-Aldrich, St.Louis, Mo., USA, unless otherwise stated.

Cell cultures. HUVECs were obtained from human umbilical cords and cultured with a partial modification of Jaffe's method [13], as previously described [14]. Pools of cells from 3 to 5 cords were grown in Medium 199 - Hepes Modification (M199), with $20 \%$ FCS, until confluent. In secondary cultures, HUVECs were kept in M199+20\% FCS + $50 \mu \mathrm{g} / \mathrm{ml}$ Endothelial Cell Growth Supplement (ECGS).

Bovine retinal pericytes (BRP) were obtained from pools of 15 to 20 bovine retinas, with a partial modification of two precedent methods $[15,16,17]$. BRP were characterized by 3G5 (a specific membrane ganglioside) fluorescence immunostaining [17] and were grown in DMEM $5.6 \mathrm{mmol} / \mathrm{l}$ glucose with $20 \%$ FCS in primary cultures and $10 \%$ FCS in secondary cultures.

ECM production by HUVEC. HUVECs in primary culture were detached by trypsin-EDTA and seeded in six-well plates (approximately $1 \times 10^{5}$ cells/well, 12500 cells $/ \mathrm{cm}^{2}$ ) with $2 \mathrm{ml}$ medium for cell counts, or in 96-well plates (approximately $5 \times 10^{3}$ cells/well, 10000 cells $/ \mathrm{cm}^{2}$ ) with $200 \mu \mathrm{l}$ medium for DNA synthesis assay. After $24 \mathrm{~h}$, medium was removed and changed with media containing 5.6 (normal) or 28 (high) $\mathrm{mmol} / \mathrm{l} \mathrm{D}$-glucose, $5.6 \mathrm{mmol} / \mathrm{l} \mathrm{D}$-glucose + $22.4 \mathrm{mmol} / \mathrm{l} \mathrm{L}$-glucose, $5.6 \mathrm{mmol} / \mathrm{l} \mathrm{D}$-glucose $+22.4 \mathrm{mmol} / \mathrm{l} \mathrm{D}$-galactose, $28 \mathrm{mmol} / \mathrm{l} \mathrm{D}$-glucose $+150 \mu \mathrm{mol} / \mathrm{l}$ thiamine or $28 \mathrm{mmol} / \mathrm{l}$ D-glucose $+7 \mathrm{mmol} / \mathrm{l}$ aminoguanidine. These media were changed every $72 \mathrm{~h}$. After 7 days in culture, the wells were washed with PBS and treated for 4 min with $0.2 \mathrm{~mol} / 1 \mathrm{NH}_{4} \mathrm{OH}$, in order to detach cells without affecting the matrix. The wells were then washed four times with PBS.

Cell proliferation - BRP counts. BRP in primary culture were detached by trypsin-EDTA and seeded in six-well plates (approximately $1 \times 10^{5}$ cells/well, 12500 cells $/ \mathrm{cm}^{2}$ ) on HUVEC- conditioned ECM. In the first series of experiments, BRP were grown for 7 days in either physiological $(5.6 \mathrm{mmol} / \mathrm{l})$ or high glucose $(28 \mathrm{mmol} / \mathrm{l})$ on ECM also produced by HUVECs in physiological or high glucose. In the following experiments, BRP were grown in normal glucose on ECM obtained by HUVECs grown in the six media described above. After 7 days of culture, BRP were detached and counted in Bürker chambers, after colouring with Trypan blue $0.2 \%$.

Cell proliferation - DNA synthesis. Incorporation of the pyrimidine analogue 5-bromo-2'-deoxyuridine (BrdU) instead of thymidine into the DNA of proliferating cells was detected by immunoassay. BRP in secondary culture were seeded in 96-well plates (approximately $5 \times 10^{3}$ cells/well, 10000 cells/ $\mathrm{cm}^{2}$ ) on ECM produced by HUVEC. After 7 days, $10 \mu \mathrm{l}$ of $100 \mu \mathrm{mol} / \mathrm{l}$ BrdU (Cell Proliferation ELISA, BrdU, Roche Diagnostics, Basel, Switzerland) in PBS was added to each well. After $24 \mathrm{~h}$ incubation at $37^{\circ} \mathrm{C}$, cells were fixed, DNA slightly denaturated, and a peroxidase-conjugated monoclonal antiBrdU antibody added at room temperature for $90 \mathrm{~min}$. After three washings with PBS, tetramethylbenzidine (TMB) was added, as a substrate for colour reaction. The reaction was stopped with $1 \mathrm{~mol} / \mathrm{l} \mathrm{H}_{2} \mathrm{SO}_{4}$ once sufficient colour had developed. Absorbances were read at $450 \mathrm{~nm}$ in an ELISA reader.

Cell cycle. After 2 days of culture on the different ECMs, BRP were fixed and permeabilized with $70 \%$ ethanol and their DNA stained with propidium iodide (Roche, $20 \mu \mathrm{g} / \mathrm{ml}$ in PBS + $0.1 \%$ BSA). Fluorescence was evaluated by flow cytometry, using FACScan equipment (Becton Dickinson Immunocytometry Systems, San José, Calif., USA). Results are expressed as percentages in a sample of 10000 cells in the different phases of the cell cycle, namely G0/G1 (cells not engaged in DNA synthesis), S (active DNA synthesis), G2 (pre-mitotic) and M (mitosis).

Apoptosis. Apoptosis was measured after 18 h, 2 days and 7 days of culture on the different ECMs by the Cell Death Detection ELISAPLUS kit (Roche), which is based on a quantitative sandwich-enzyme-immunoassay principle, using monoclonal antibodies directed against DNA and histones. This allows the specific determination of mono- and oligonucleosomes in the cytoplasmatic fraction of cell lysates. As a control, apoptosis was also measured in BRP cultured directly in 5.6 or $28 \mathrm{mmol} / \mathrm{l} \mathrm{D}$-glucose at 2 days and 7 days.

To confirm data obtained with ELISA, apoptosis was also measured by FACS, by direct staining of BRP, after 2 days of culture on the relevant ECMs, with annexin-V-FLUOS (20 $\mu \mathrm{l} / \mathrm{ml}$, Roche) and propidium iodide $(1 \mu \mathrm{g} / \mathrm{ml})$ in Hepesbuffered saline. Annexin- $\mathrm{V}$ is a $\mathrm{Ca}^{2+}$-dependent phospholipidbinding protein, with high affinity for phosphatidylserines, which are translocated from the interior side of the plasma membrane to the outer leaflet in early stages of apoptosis. Since necrotic cells also expose phosphatidylserines, propidium iodide was used for a dye exclusion test.

Experiments with ECM glycoproteins. Plates (6-well plates or 96-well plates) were coated overnight at $37^{\circ} \mathrm{C}$ with either laminin $(0,10,50 \mu \mathrm{g} / \mathrm{ml}$ in PBS), fibronectin $(0,10,50 \mu \mathrm{g} / \mathrm{ml}$ in PBS) or type IV collagen $(0,10,50 \mu \mathrm{g} / \mathrm{ml}$ in PBS). Plates were then washed with PBS and BRP in secondary culture and seeded, as described above, in medium with either 5.6 or $28 \mathrm{mmol} / 1$ glucose. Cell counts and DNA synthesis assays were then carried out at 7 days.

Statistical analysis. Due to batch-to-batch variations, data are expressed as percentages (means \pm SD) of the results obtained 
with positive control conditions (i.e. ECM obtained from HUVEC grown in $5.6 \mathrm{mmol} / \mathrm{l}$ glucose alone) within each experiment, unless otherwise stated. Statistical comparisons between groups was carried out by Wilcoxon's signed rank test. A $p$-value of 0.05 or less was considered statistically significant.

\section{Results}

\section{BRP replication on HUVEC-conditioned ECM}

Cell counts. BRP grown in normal glucose on ECM obtained from HUVEC cultured in high glucose $(n=7)$ were less numerous $(86.3 \pm 6.3 \%, p=0.016)$ than the positive control. BRP in high glucose were reduced on ECM obtained in both normal $(83.2 \pm 7.2 \%, p=0.016)$ and high glucose $(68.1 \pm 9.4 \%, p=0.016$ vs both positive control and BRP in high glucose on ECM in normal glucose) (Fig. 1). To rule out the possibility that glucose attachment to the plastic of culture plates was responsible for this result independent of matrix formation, 6-well plates were incubated for 7 days with culture media containing normal and high glucose but no HUVECs. The media were then removed and BRP seeded and kept for another 7 days in normal glucose without finding any differences in the final counts (data not shown).

In a subsequent series of experiments $(n=10)$, BRP were cultured for 7 days in $5.6 \mathrm{mmol} / \mathrm{l}$ glucose, on different ECMs. BRP grown on ECM obtained in high glucose were $76.8 \pm 8.8 \%$ of the positive control $(p=0.002)$. Those cultured on ECM obtained in high D-galactose were $86.0 \pm 18.0 \%$ of control $(p=0.037)$, those in high L-glucose were $96.4 \pm 31.3 \%$ of control $(p=\mathrm{NS})$, those in high $\mathrm{D}$-glucose + aminoguanidine were $96.6 \pm 14.7 \%$ ( $p=\mathrm{NS}$ vs normal glucose, $p=0.006$

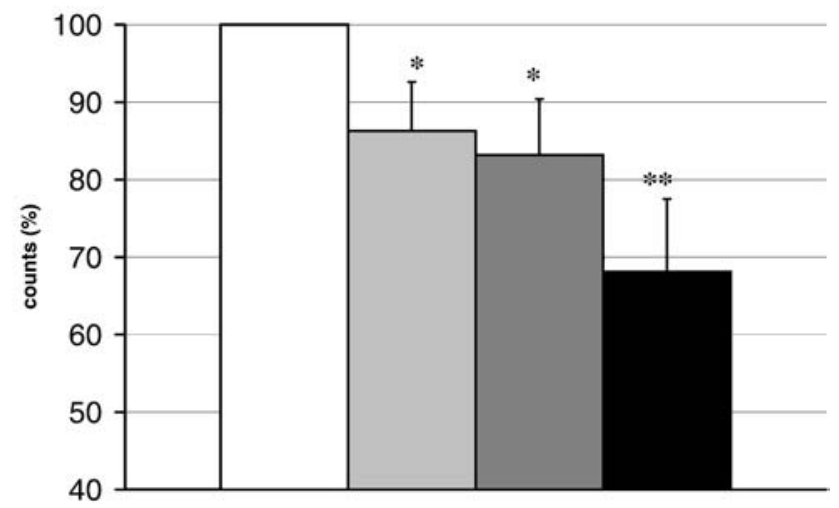

Fig. 1. BRP grown in $5.6 \mathrm{mmol} / \mathrm{l}$ glucose on ECM obtained from HUVECs cultured in 5.6 (white bar - positive control) or $28 \mathrm{mmol} / \mathrm{l}$ (light grey bar) D-glucose; BRP grown in $28 \mathrm{mmol} / \mathrm{l}$ glucose on ECM obtained from HUVECs cultured in 5.6 (dark grey bar) or $28 \mathrm{mmol} / \mathrm{l}$ (black bar) D-glucose, expressed as percentages of positive control. $* p=0.016$ vs positive control, $* * p=0.016$ vs both positive control and BRP in high glucose on ECM in normal glucose vs high D-glucose) and those in high D-glucose + thiamine were $92.2 \pm 21.3 \%$ ( $p=\mathrm{NS}$ vs normal glucose, $p=0.037$ vs high D-glucose) (Fig. 2).

DNA synthesis. BrdU incorporation $(n=8)$ was: $89.0 \pm 8.8 \%$ of control in high D-glucose $(p=0.008)$, $88.3 \pm 4.3 \%$ in high D-galactose $(p=0.008), 93.2 \pm 6.4 \%$ in high L-glucose $(p=0.016), 97.5 \pm 8.8 \%$ in high Dglucose + aminoguanidine $(p=\mathrm{NS}$ vs control, $p=0.054$ vs high D-glucose), and $97.1 \pm 5.1 \%$ in high D-glucose + thiamine ( $p=\mathrm{NS}$ vs control, $p=0.016$ vs high D-glucose) (Fig. 3).

Cell cycle. Flow cytometry analysis for DNA content $(n=6)$ showed no differences in the distribution along

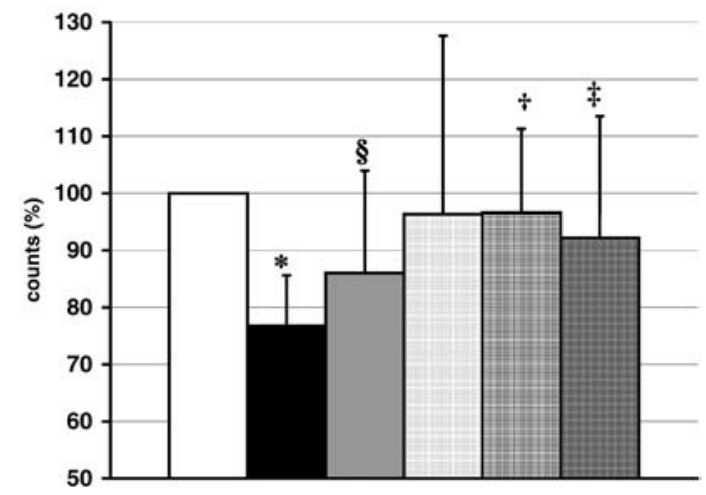

Fig. 2. Counts of BRP grown in normal glucose on ECM produced in normal glucose (positive control, white), high D-glucose (black), high D-galactose (grey), high L-glucose (dots), high D-glucose + aminoguanidine (squares), high D-glucose + thiamine (diagonals), expressed as percentages of positive control. * $p=0.002$ vs ECM in normal glucose, $\S p=0.037$ vs $\mathrm{ECM}$ in normal glucose, $\dagger p=0.006$ vs high D-glucose, $\ddagger p=0.037$ vs high D-glucose

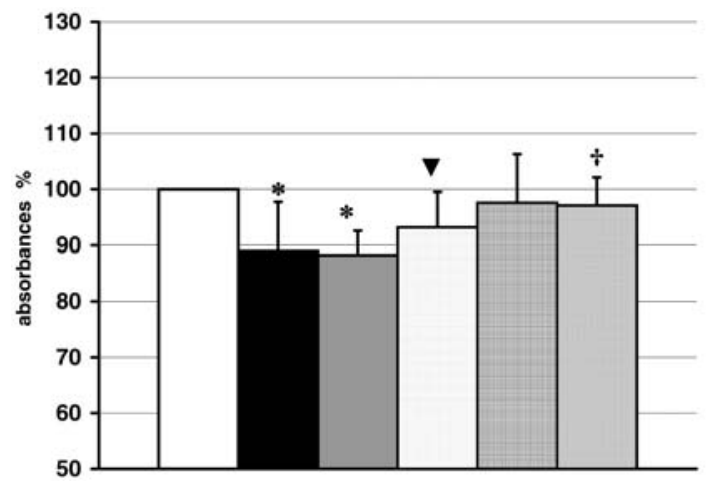

Fig. 3. BrdU incorporation in BRP grown in normal glucose on ECM produced in normal glucose (positive control, white), high D-glucose (black), high D-galactose (grey), high Lglucose (dots), high D-glucose + aminoguanidine (squares), high D-glucose + thiamine (diagonals), expressed as percentages of positive control. * $p=0.008$ vs ECM in normal glucose, $\nabla p=0.016$ vs ECM in normal glucose, $\dagger p=0.016$ vs high D-glucose 


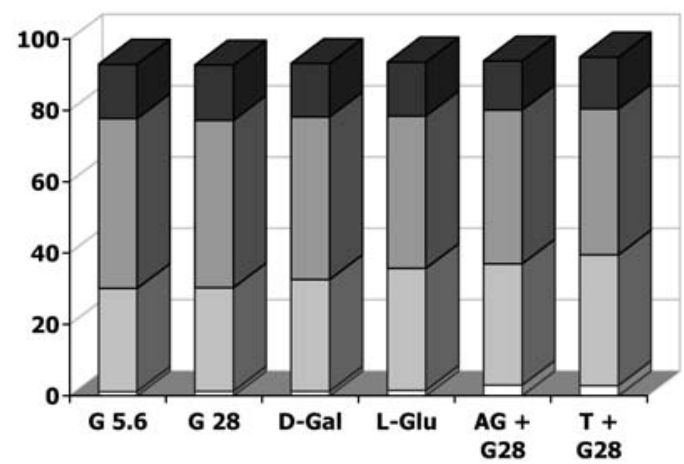

Fig. 4. Effects of conditioned-ECM on BRP cell cycle $(n=6)$. Each gradation of grey represents one phase of the cycle: white - apoptosis; light grey - G0/G1; dark grey - S; black G2/M. No differences were found



Fig. 5. Effects of conditioned-ECM on BRP apoptosis, FACS $(n=6)$. White - viable cells; grey - cells in necrosis; black cells in apoptosis. No differences were found

the cell cycle of BRP cultured on the different ECMs (Fig. 4).

Apoptosis. Apoptotic index measured by ELISA ( $n=6$ ) did not show any differences at any time between the experimental conditions and the relevant positive $(5.6 \mathrm{mmol} / \mathrm{l} \mathrm{D}$-glucose) and negative $(28 \mathrm{mmol} / \mathrm{l}$ D-glucose) controls (Table 1). On the contrary, apoptosis was higher if BRP were cultured directly in high D-glucose.

These results were confirmed by FACS analysis, where again we could not find any difference, when BRP were cultured on the six different ECMs (Fig. 5).

$B R P$ replication and adhesion on plates coated with ECM glycoproteins. No consistent changes were found in cell counts and BrdU incorporation of BRP seeded in culture wells pre-treated with laminin and fibronectin. In the case of type IV collagen, significant dose-dependent decreases in cells counts were observed after 7 days in culture, though not in BrdU incorporation (Table 2).

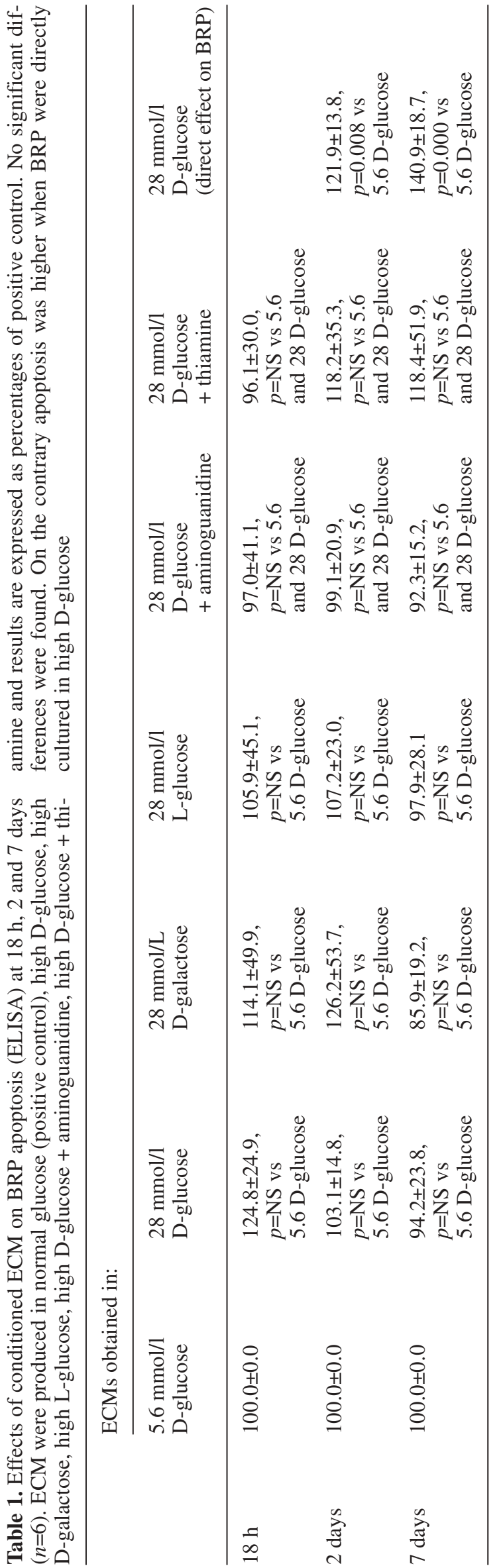




\section{Discussion}

These results suggest that pericytes seeded on ECM produced by endothelial cells in high glucose replicate with a pattern similar to their initial adhesion rate [12]. As a consequence, reduced BRP counts and BrdU uptake at day 7 could have resulted from similarly reduced adhesion to the different substrates at the time of seeding with a minor number of cells available to start dividing. That modifications of pericyte viability were unlikely to be involved is confirmed by the observation that neither cell cycle, nor apoptosis were affected by culture on these conditioned ECMs. The similar behaviour of pericyte adhesion and replication, regular checking by the vital dye Trypan blue at the time of counting the cells and the negative results obtained with the cell cycle and apoptosis measurements seem to rule out a role for cell death, apoptosis and/or abnormalities of the cell cycle traversal. On the contrary, in control experiments, BRP confirmed increased apoptosis when directly exposed to high glucose [18].

D-galactose is partially metabolised by the cell and could be transformed into D-glucose via the UDPhexose pathway involved in the synthesis of glycogen and glycoproteins. Normal rats fed a high D-galactose diet develop a retinopathy very similar to that of diabetic rats [4]. L-glucose is internalized but not metabolized. All three hexoses tested are able to directly induce non-enzymatic glycosilation of intra- and extracellular proteins [7], whereas only D-glucose and, possibly, D-galactose might do so indirectly, through their metabolites. D-glucose and D-galactose need quite long periods to directly glycate, while some of their metabolites, such as glucose-6-phosphate, fructose-6-phosphate, glyceraldehyde-3-phosphate and a polyol pathway-related metabolite, fructose-3-phosphate, are able to produce AGEs within $24 \mathrm{~h}[19,20]$. Thiamine acts as a coenzyme for transketolase, which shifts glyceraldehyde-3-phosphate towards the pentose phosphate cycle, for pyruvate-dehydrogenase which transforms pyruvate in acetyl-CoA and for $\alpha-$ keto-glutarate-dehydrogenase, which catalyses the oxidation of ketoglutaric acid to succinyl-CoA within the Krebs cycle [14, 21, 22]. Aminoguanidine inhibits the progression of labile adducts to permanent AGEs [19]. The short exposure of endothelial cells to high hexose and to thiamine and aminoguanidine in our work is consistent with the observation that glycation was mediated by intermediate glycolysis metabolites, rather than by direct action of D-glucose and D-galactose and that aminoguanidine and thiamine could inhibit initial stages of glycation [12, 23]. The smaller effect of L-glucose (confirmed by BrdU incorporation, but not by cell counts) might support a minor role also for direct glycation and/or osmotic mechanisms.

Impaired replication of endothelium on ECM obtained from other endothelial cells previously grown 
in high glucose concentrations was described previously $[7,24]$ and a role for excess exogenous fibronectin, altering cell-ECM interactions through increased adhesion and cytoskeletal rearrangements, was hypothesized [5]. High glucose was shown to increase type IV collagen and fibronectin mRNA synthesis [25] and to upregulate the trascription of their genes [7] in cultured human endothelial cells. Augmented synthesis of basement membrane collagen in the retina [26] and of collagen [27], laminin [28] and fibronectin [29] in kidney glomeruli were shown in diabetic rats, while fibronectin immunostaining is increased in the retina of diabetic subjects with background retinopathy [30]. Consistent with our previous observation that pericyte adhesion is not modified by increasing concentrations of laminin, fibronectin or type IV collagen [12], we were also unable to observe an influence on BRP replication at day 7. Decrease of BRP counts on plates pretreated with $50 \mu \mathrm{g} / \mathrm{ml}$ type IV collagen was presumably an artefact, as the cells became more adherent after 7 days than in any other experimental condition. Since they could not be neatly detached for counting even after $30 \mathrm{~min}$ in trypsinEDTA (they usually detach within 5-10 minutes), mechanical removal by scraping could have caused part of the cells either to be lost or remain aggregated in clumps. Since no consistent changes were observed in adhesion or replication of BRP on increasing concentrations of laminin, fibronectin and type IV collagen, a role of these glycoproteins in pericyte adhesion and/or replication on HUVEC-conditioned ECM in our system could be ruled out.

Bovine retinal pericytes are particularly vulnerable to the effects of high glucose, as their replication is impaired at concentrations that do not affect bovine retinal endothelial cells [31]. If these observations hold true in human capillaries, then inhibition of pericyte replication and increased apoptosis, as directly induced by high blood glucose, could be compounded indirectly by altered interactions with ECM secreted, in the diabetic milieu, by nearby endothelium. Pericytes have a very low turnover rate [32], suggesting that acute effects observed in cell culture conditions could take years to develop. Further research is required to elucidate the nature of such interactions, their role in the pathogenesis of diabetic retinopathy and the potential beneficial effects of thiamine.

Acknowledgments. This work was supported by grants from the University of Turin (Fondi ex-60\%) and the Italian Ministry of Health.

\section{References}

1. Østerby R (1983) Basement membrane morphology in diabetes mellitus. In: Ellenberg M, Rifkin H (eds) Diabetes mellitus, theory and practice, $3^{\text {rd }}$ edn. Med Exam, New York, pp 323-341
2. Siperstein MD (1988) Diabetic microangiopathy, genetics, enviroment, and treatment. Am J Med 85 [Suppl 5A]:119130

3. Engerman RL (1989) Pathogenesis of diabetic retinopathy. Diabetes 38:1203-1206

4. Kern TS, Engerman RL (1994) Comparison of retinal lesions in alloxan-diabetic rats and galactose-fed rats. Curr Eye Res 13:863-867

5. Podestà F, Roth T, Ferrara F, Cagliero E, Lorenzi M (1997) Cytoskeletal changes induced by excess extracellular matrix impair endothelial cell replication. Diabetologia 40: 879-886

6. Feige JJ, Bradley JD, Fryburg K et al. (1989) Differential effects of heparin, fibronectin, and laminin on the phosphorylation of basic fibroblast growth factor by protein kinase $\mathrm{C}$ and the catalytic subunit of protein kinase A. J Cell Biol 109:3105-3114

7. Cagliero E, Roth T, Roy S, Lorenzi M (1991) Characteristics and mechanisms of high-glucose-induced overexpression of basement membrane components in cultured human endothelial cells. Diabetes 40:102-110

8. Paul RG, Bailey AJ (1999) The effect of advanced glycation end-product formation upon cell-matrix interactions. Int J Biochem Cell Biol 31:653-660

9. Singh R, Barden A, Mori T, Beilin L (2001) Advanced glycation end-products: a review. Diabetologia 44:129-146

10. Kohner EM (1991) The lesions and natural history of diabetic retinopathy. In: Pickup J, Williams G (eds) Textbook of diabetes. Blackwell, Oxford, pp 575-588

11. Cogan DG, Kubawara T (1967) The mural cell in perspective. Arch Ophtalmol 78:133-139

12. Beltramo E, Pomero F, Allione A, D'Alù F, Ponte E, Porta M (2002) Pericyte adhesion is impaired on extracellular matrix produced by endothelial cells in high hexose concentrations. Diabetologia 45:416-419

13. Jaffe EA, Nachman RL, Becker CG, Minick CR (1973) Culture of human endothelial cells derived from umbilical veins. Identification by morphologic and immunologic criteria. J Clin Invest 52:2745-2756

14. La Selva M, Beltramo E, Pagnozzi F et al. (1996) Thiamine corrects delayed replication and decreases production of lactate and advanced glycation end-products in bovine retinal and human umbilical vein endothelial cells cultured under high glucose conditions. Diabetologia 39:1263-1268

15. Wong HC, Boulton M, Marshall J, Clark P (1987) Growth of retinal capillary endothelial cells using pericyte conditioned medium. Invest Opthalmol Vis Sci 28:1767-1775

16. McIntosh LC, Muckersie L, Forrester JV (1988) Retinal capillary endothelial cells prefer different substrates for growth and migration. Tissue Cell 20:193-209

17. Brignardello E, Beltramo E, Molinatti PA et al. (1998) Dehydroepiandrosterone protects bovine retinal capillary pericytes against glucose toxicity. J Endocrinol 158:21-26

18. Podestà F, Romeo G, Liu W-H et al. (2000) Bax is increased in the retina of diabetic subjects and is associated with pericyte apoptosis in vivo and in vitro. Am J Pathol 156:1025-1032

19. Brownlee M (1994) Glycation and diabetic complications. Diabetes 43:836-841

20. Hamada Y, Araki N, Koh N, Nakamura J, Horiuchi S, Hotta N (1996) Rapid formation of advanced glycation end products by intermediate meabolites of glycolytic pathway and polyol pathway. Biochem Biophys Res Commun 228:539-543

21. Booth AA, Khalifah RG, Hudson BG (1996) Thiamine pyrophosphate and pyridoxamine inhibit the formation of antigenic advanced glycation end-products: comparison with 
E. Beltramo et al.: A study of capillary pericyte viability on extracellular matrix produced by endothelial cells

aminoguanidine. Biochem Biophys Res Commun 220: 113-119

22. Thornalley PJ, Jahan I, Ng R (2001) Suppression of the accumulation of triosephosphates and increased formation of methylglyoxal in human red blood cells during hyperglycaemia by thiamine in vitro. J Biochem 129:543-549

23. Booth AA, Khalifah RG, Todd P, Hudson BG (1997) In vitro kinetic studies of formation of antigenic advanced glycation end products (AGEs). Novel inhibition of postAmadori glycation pathways. J Biol Chem 272:5430-5437

24. Roth T, Podestà F, Stepp MA, Boeri D, Lorenzi M (1993) Integrin overexpression induced by high glucose and by human diabetes: potential pathways to cell dysfunction in diabetic microangiopathy. Proc Natl Acad Sci USA 90: 9640-9644

25. Cagliero E, Maiello M, Boeri D, Roy S, Lorenzi M (1988) Increased expression of basement membrane components in human endothelial cells cultured in high glucose. J Clin Invest 82:735-738

26. Reddi AS (1985) Collagen metabolism in the retina of normal and diabetic rats. Exp Eye Res 41:345-352
27. Brownlee M, Spiro RG (1979) Glomerular basement membrane metabolism in the diabetic rat: in vivo studies. Diabetes 28:121-125

28. Poulsom R, Kurkinen M, Prockop DJ, Boot-Handford RP (1988) Increased steady-state levels of laminin B1 mRNA in kidneys of long-term streptozotocin-diabetic rats. J Biol Chem 263:10072-10076

29. Roy S, Sala R, Cagliero E, Lorenzi M (1990) Overexpression of fibronectin induced by diabetes or high glucose: phenomenon with a memory. Proc Natl Acad Sci USA 87:404-408

30. Roy S, Cagliero E, Lorenzi M (1996) Fibronectin overexpression in retinal microvessels of patients with diabetes. Invest Ophthalmol Vis Sci 37:258-266

31. Porta M, Molinatti PA, Dosso A, Williams FMK, Brooks RA, Kohner EM (1994) Growth of bovine retinal pericytes and endothelial cells in high hexose concentrations. Diabetes Metab 20:25-30

32. Engerman RL, Pfaffenbach D, Davis MD (1967) Cell turnover of capillaries. Lab Invest 17:738-743. 